\title{
Quantile Dependence between the Stock, Bond and Foreign Exchange Markets - Evidence from the UK
}

\author{
Hamid Raza* $\quad$ Weiou $\mathrm{Wu}^{\dagger}$
}

October 27, 2016

\begin{abstract}
In the wake of Brexit, this paper aims to provide a measure for the quantile dependence amongst different financial assets - bond, stock, and currency - within the UK market and their cross-border linkages with the European equity market. We implement a nonparametric estimation method for both the tail and quantile dependence parameters on weekly data over the period 1989-2016 using copula. Our results suggest that the contagion effect between stock and currency markets is limited, even under extreme fluctuations. We also find weak comovement between currency and bond markets, however, evidence of asymmetry is found in the dependence structure, possibly due to the 'risk-reward' scenario of international investors. Finally, our results indicate a weak dependence between stock returns and bond yields, possibly due to the low-yielding gilt and the thirst for income which push investors to diversify more thoroughly into other financial markets.
\end{abstract}

Keywords: Quantile Dependence, Copula, Nonparametric Estimation, Asymmetric Dependence

JEL Codes: C22, G12

*Department of Business and Management, MaMTEP, Aalborg University, Denmark. Email: raza@business.aau.dk

${ }^{\dagger}$ Corresponding Author: Accounting, Finance and Economics Division, School of Business, London South Bank University, UK. Email: wuw6@lsbu.ac.uk 


\title{
Quantile Dependence between the Stock, Bond and Foreign Exchange Markets - Evidence from the UK
}

\author{
October 31, 2017
}

\begin{abstract}
In the wake of Brexit, this paper aims to provide a measure for the quantile dependence amongst different financial assets - bond, stock, and currency - within the UK market and their cross-border linkages with the European equity market. We implement a nonparametric estimation method for both the tail and quantile dependence parameters on weekly data over the period 1989-2016 using copula. Our results suggest that the contagion effects between stock and currency markets are limited, even under extreme fluctuations. We also find a weak comovement between currency and bond markets, however, evidence of asymmetry is found in the dependence structure, possibly due to the 'risk-reward' scenario of international investors. Finally, our results indicate a weak dependence between stock returns and bond yields, possibly due to the low-yielding gilt and the thirst for income, pushing investors to diversify globally into other financial markets.
\end{abstract}

Keywords: Quantile Dependence, Copula, Nonparametric Estimation, Asymmetric Dependence

JEL Codes: C22, G12

\section{Introduction}

Britain's vote to leave the EU - the country's biggest decision in more than a generation - has shifted the European financial markets into a phase of greater uncertainty. In the immediate aftermath of the British referendum, the sterling dropped more than 10 percent against the dollar within a single day, hitting its lowest level for over three decades. The British stock market initially dropped but later on recovered to its pre-shock levels. In the meantime, the benchmark UK interest rate as represented by the 10-year gilt yield dropped to a record low, reflecting expectations of sharp reductions in the interest rate.

This brief but a strong wave of panic in the UK also generated concerns amongst investors in the EU markets. The Stoxx 600, a major gauge of stocks across the European continent, dropped by $7 \%$ immediately, clearly reflecting a 'spillover effect' of the UK market on its trading partners. The indicators of business and consumers have sharply declined. The country's credit rating dropped from top AAA to AA for the first time since 1978. A slowdown in real economic growth is forecasted and quantitative easing, as 
a policy response, is widely expected.

These recent developments clearly reflect market anxiety over UK's path towards an official 'exit' (Brexit) from the EU, and its consequences. A less stable and an unpredictable environment in the UK will have negative effects on its domestic economy as well as on the rest of the EU, which is still in the recovery phase after the 2008 crisis. ${ }^{1}$ While the situation for the time being has calmed down, swings in the financial markets are expected with new developments regarding Brexit. In this regard, an important question which needs to be addressed is how strong is the dependence amongst different asset markets within the UK namely, currency, stock and bond markets, and their cross-border dependence with the EU equity market.

There is a large pile of literature on the linkages amongst currency, equities, and bonds within a single market as well as across the global markets. ${ }^{2}$ Following the global financial crisis, a large number of recent studies have focused on either the crisis-hit markets (Chuliá et al., 2010; Garcia and Tsafack, 2011; Syllignakis and Kouretas, 2011; Grammatikos and Vermeulen, 2012; Bekaert et al., 2013) or the emerging international markets (Panchenko and Wu, 2009; Lin, 2012). The British market due to its relatively stable history has not received considerable attention in the last decade. The analyses of the British market have been included as a side story in many studies (see, e.g., Cumperayot et al., 2006; Hau and Rey, 2006; Ning, 2010; Kenourgios et al., 2011; Inci and Lee, 2014). ${ }^{3}$ Consequently, a discussion of the dependence structure amongst currency, equity and bond markets within the UK as well as their cross-border linkages with the EU equity market is clearly lacking. In the wake of Brexit, it is therefore vital to conduct an explicit investigation of the British and the EU markets using the latest information, and offer more empirical insights. Studying the co-movements within the British financial markets and its cross-border linkages with the EU market is important for the purpose of risk and portfolio management, which could improve diversification or hedging opportunities.

This paper models the dependence in all quadrants of the joint distribution amongst different assets in the UK and their co-movements with the EU equity market for a relatively long period from 1989 to 2016. In particular, it explores the probability that returns of one market are (extremely) positive/negative, given that returns of the other one are (extremely) positive/negative. We study the dependence structure beyond the conventional dependence measure - Pearson correlation - which despite being widely adopted is appropriate only for linear association or when extreme realisations are not a concern. In total eight dependence structures are modelled between the equity markets (using FTSE 100 index, FTSE 250 index and Stoxx 600 index), the bond market (using UK 10-year gilt yield), and the currency market (using the rate for USD per GBP

\footnotetext{
${ }^{1}$ In addition, Italy is currently facing a banking crisis, which is probably the second biggest challenge to the EU after Brexit.

${ }^{2}$ See, for example, Baig and Goldfajn (1999); Phylaktis and Ravazzolo (2005); Guidolin and Timmermann (2006); Gravelle et al. (2006); Dungey and Martin (2007); Gagnon (2009).

${ }^{3}$ Most of the recent studies while resting on conventional estimation methods have focused on different dimensions of financial markets such as causality (Alagidede et al., 2011; Tudor and Popescu-Dutaa, 2012), transmission channels (Ehrmann et al., 2011; Grammatikos and Vermeulen, 2012), financial integration (Kim et al., 2006; Panchenko and Wu, 2009; Yu et al., 2010; Bekaert et al., 2013), etc.
} 
dollars). To provide a consistent analysis across dependence measures, both tail dependence and quantile dependence are modelled non-parametrically. The tail dependence is modelled by the nonparametric estimator using copula proposed by Frahm et al. (2005) while for quantile dependence, we follow the classic definition of quantile using copula as found in a large strand of literature (see, for example, Joe, 1997; Frahm et al., 2005; Patton, 2013). To check the robustness of our results, estimates from nonparametric tail dependence models are also compared with estimates from parametric models.

Our paper has three core contributions: i) To our knowledge, this is the first paper that investigates the dependence structure amongst currency, equity, and bond markets in the UK, and their cross-border linkages with the EU equity market. ii) The paper adopts a novel econometric model by using copula. In particular, we draw extreme value theory and consider the quantile dependence measure, which (in its classical definition) quantifies the strength of dependence between two variables when they are jointly low or high. iii) We provide empirical insights on the British markets using latest data, offering vital information for the ongoing debate on Brexit.

The remainder of this paper is organised as follows. Section 2 discusses the models for the marginal distributions and the estimators used for tail and quantile dependence coefficients. Section 3 provides some descriptive statistics of the data. Section 4 presents the results for the marginal distributions. Section 5 and 6 build models for the bivariate tails as well as for each quadrants of the joint distribution. Section 7 concludes the paper.

\section{Methodology}

This paper adopts an approach to model dependence between stock, bond and foreign exchange markets beyond the conventional dependence measure. We draw on extreme value theory and model both the tail and quantile dependence using copula. A copula defines the degree and structure of the dependence between two random variables. The joint distribution can be expressed in terms of the marginal distributions and a copula, while the marginal distribution functions contain all the information of the margins. Therefore, the copula contains all information regarding the dependence structure between the two random variables.

\subsection{Models for the Marginal Distribution}

Following Patton (2006a)'s two-stage estimation methods, we first estimate the marginal distributions of all series. Given the potential asymmetry between negative and positive shocks, ARMA-GJR-GARCH models were adapted for the marginal distributions, which can be expressed as

$$
\begin{aligned}
& r_{t}=\mu+\varepsilon_{t}, t=1,2, \ldots, T \\
& E\left(\varepsilon_{t}^{2}\right)=h_{t}
\end{aligned}
$$

where $r_{t}$ is the asset return, $\mu$ is the conditional mean that may include, for example, autoregressive term and $\varepsilon_{t}$ is the error term. The conditional variance of the GJR model 
is given by

$$
\begin{gathered}
\sigma_{t}^{2}=\alpha_{0}+\alpha_{1} u_{t-1}^{2}+\beta \sigma_{t-1}^{2}+\gamma u_{t-1}^{2} I_{t-1}, \\
\text { where } I_{t-1}= \begin{cases}1 & \text { if } u_{t-1}<0 \\
0 & \text { if otherwise }\end{cases}
\end{gathered}
$$

In the GJR-GARCH model, if $\gamma>0$, then negative innovations (unanticipated price falls) are more destabilising than positive innovations.

We will consider a nonparametric approach for the standardised residuals obtained from the above models. Chen and Fan (2006) argued that the copula parameters could be affected by a possibly misspecified marginal distribution of the standardised residuals. Thus, they suggested a non-parametric estimation based on an empirical copula, where the margins are specified by the empirical distribution function (EDF).

The empirical distribution function can be used when the distribution of the margins are unknown. Therefore, it is likely to be more consistent than the parametric method used in Patton (2006a,b), Jondeau and Rockinger (2006) and Zhang et al. (2009) amongst others, which requires the knowledge of the distribution of innovations, and is likely to be inconsistent if one or more margins are misspecified. Genest and Rivest (1995) provides the consistency and asymptotic normality property of the copula parameter for the non-parametric estimation method. The EDF has the following expression:

$$
\hat{u}_{i t}=\hat{F}_{i}\left(x_{i t}\right)=\frac{1}{T+1} \sum_{j=1}^{T} I\left\{X_{i j} \leq x_{i t}\right\}
$$

where $I(\Theta)$ is the indicator of the event $\Theta, \hat{F}_{i}$ is cumulative distribution functions of $X_{i}$ and $x_{i t}$ is the return series of a financial asset. Then the joint distribution of $X$ and $Y$ can be expressed in terms of a copula and empirical marginal distributions:

$$
\hat{H}(x, y)=C\left(\hat{F}_{x}(X), \hat{F}_{y}(Y)\right)
$$

where $\hat{H}, \hat{F}_{x}, \hat{F}_{y}$ denote the empirical distributions.

\subsection{Estimating the Tail Dependence Coefficient}

Tail dependence is a measure of the dependence between extreme events in the lowerleft-quadrant or up-right-quadrant tail of a bivariate distribution. The traditional tail dependence can be written in terms of copula. If $C$ is the copula of two random variables $X$ and $Y$, then

$$
\lambda_{L}=\lim _{q \rightarrow 0^{+}} \frac{C(q, q)}{q} \text { and } \lambda_{U}=\lim _{q \rightarrow 1^{-}} \frac{1-2 q+C(q, q)}{1-q}
$$

The upper tail dependence can be further written into

$$
\lambda_{U}=2-\frac{1-C(q, q)}{1-q} \sim 2-\frac{\log C(q, q)}{\log q} \text { as } q \rightarrow 1
$$


In this paper, we use the non-parametric estimator proposed by Frahm et al. (2005) for the estimation of the above tail dependence. The upper tail dependence is measured as

$$
\hat{\lambda}^{U}=2-\frac{\log \hat{C}_{m}((m-k) / m,(m-k) / m)}{\log ((m-k) / m)}, 0<k<m
$$

where

$$
\hat{C}_{m}(U, V)=\frac{1}{m} \sum_{j=1}^{m} \mathbf{1}\left(\frac{R_{1 j}}{m} \leqslant U, \frac{R_{2 j}}{m} \leqslant V\right)
$$

is called the empirical copula. 1 denotes the indicator function, $k$ is the threshold and $R$ is the rank of the block maxima. This measure of extremal dependence is well behaved for all thresholds $k$ in terms of bias, if the bivariate data are stochastically independence (Frahm et al., 2005).

It is well known that the choice of a threshold level for the quantile $q$ for which tail dependence is empirically estimated involves a trade-off between the estimator and its bias. That is, the smaller $q$, the larger the variance and vice versa. Frahm et al. (2005) suggest that the way to protect against any misspecification is the application of difference estimators on the same datasets. Therefore, we check the results of our tail dependence using another nonparametric estimator, the "SEC" estimator from Frahm et al. (2005), which has the following expression:

$$
\hat{\lambda}_{U}^{S E C}=2-\frac{\left.1-\hat{C}_{m}(m-k / m),(m-k) / m\right)}{1-(m-k) / m}, 0<k \leqslant m
$$

Asymptotic normality and strong consistency of the second estimator are addressed in Schmidt and Stadtmuller (2006).

\subsection{Modelling Quantile Dependence using a Copula}

Tail dependence by definition does not characterise the complete dependence structure between two variables, including the dependence between non-extreme events (see, for example, Joe, 1997; Frahm et al., 2005; Patton, 2013). That is, tail dependence only captures the probability that an extreme event occurs in one market given that an extreme event has already occurred in another market. Hence, there is lost information associated with non-extreme events, which leave a large portion of useful information unexplained when modelling correlation.

To overcome the above problem, we consider dependence at different quantile levels in this paper in order to provide a richer description of the dependence structure of two random variables. The quantile dependence is defined as without providing the limit to 
Equation (6), that is

$$
\begin{aligned}
\lambda^{q} & =\left\{\begin{array}{c}
\operatorname{Pr}\left[U_{1 t} \leq q \mid U_{2 t} \leq q\right], 0<q \leq 1 / 2 \\
\operatorname{Pr}\left[U_{1 t}>q \mid U_{2 t}>q\right], 1 / 2<q<1
\end{array}\right. \\
& =\left\{\begin{array}{c}
\frac{C(q, q)}{q}, 0<q \leq 1 / 2 \\
\frac{1-2 q+C(q, q)}{1-q}, 1 / 2<q<1
\end{array}\right.
\end{aligned}
$$

with empirical estimation achieved by

$$
\hat{\lambda}^{q}=\left\{\begin{aligned}
\frac{1}{T q} \sum_{t=1}^{T} \mathbf{1}\left\{U_{1 t} \leq q, U_{2 t} \leq q\right\}, 0<q \leq 1 / 2 \\
\frac{1}{T(1-q)} \sum_{t=1}^{T} \mathbf{1}\left\{U_{1 t}>q, U_{2 t}>q\right\}, 1 / 2<q<1
\end{aligned}\right.
$$

The joint upper and joint lower tails are modelled separately. By comparing the upper and lower tails we provide more detailed information on co-movements of different levels of strength. Furthermore, a test for asymmetric dependency is provided. The null hypothesis for a simple test of asymmetric dependence is

$$
\lambda^{q}=\lambda^{1-q}, \text { for all } q \in(0,1)
$$

against

$$
\lambda^{q} \neq \lambda^{1-q}, \text { for some } q \in(0,1)
$$

However, testing the equality of the upper and lower dependence structure as illustrated above provides a necessary but not sufficient condition for asymmetric dependence. Rather than testing each $q$ separately, and run into problem of interpreting a set of multiple correlated individual tests, it is desirable to test for asymmetry jointly.

Following the test proposed by Hong et al. (2007), we generate a sample of $\lambda^{+}-\lambda^{-}$, where

$$
\lambda^{+}-\lambda^{-}=\left[\lambda^{+}\left(q_{1}\right)-\lambda^{-}\left(1-q_{1}\right), \ldots, \lambda^{+}\left(q_{m}\right)-\lambda^{-}\left(1-q_{m}\right)\right]^{\prime}
$$

where $q_{m} \in(0,0.5)$, and their test statistic is

$$
\Theta_{\lambda}=T\left(\lambda^{+}-\lambda^{-}\right)^{\prime} \Pi^{-1}\left(\lambda^{+}-\lambda^{-}\right)
$$

where $T$ is the number of observations, $\Pi$ is a heteroscedasticity and autocorrelation (HAC) robust covariance estimator like the one proposed by Newey and West (1994). Implementing this test on the estimated tail and quantile function yields a statistic and a corresponding $p$-value. This statistic is shown to asymptotically follow a chi-square distribution with $m$ degrees of freedom.

\section{Data}

For our analyses, we use weekly time-series data for the period January 1989 to August 2016, obtained from Bloomberg. We use FTSE 100 and FTSE 250 indices to capture movements in the UK stock markets while using the Stoxx 600 index for the EU stock 
market. In addition, we use 10-year gilt yields and an index for the currency market, which is the nominal exchange rate for USD per GBP dollars.

Figure 1 shows the weekly time series of the variables used in our analysis. There is a clear positive co-movement between FTSE 100 index and Euro Stoxx index. It is clear that both series exhibit the same trend before and during the recent financial crisis. However, in the post-crisis period, the recovery in FTSE 100 is relatively faster than in the Stoxx 600 index. The sluggish recovery of Stoxx could possibly be due to the effect of the Eurozone Sovereign debt crises on the equity market.

There are a few large swings in the UK currency market over the last two and a half decades: the fall in the early 1990s was due to 'Black Wednesday', when Britain was forced to exit the Exchange Rate Mechanism (ERM). The next episode of swings in the currency market occurred in the 2000s with the appreciation of the pound prior to the 2008 crisis, and then the depreciation during the crisis. Since the onset of the 2008 crisis, the currency market stabilised until the recent event of Brexit.

The yield on 10-year gilt shows a declining trend since the 1990s. The declining trend in the time series can be explained by various historic episodes, which we will not address in this paper. ${ }^{4}$ However, the fall in the interest rates after the 2008 crisis can be largely explained by quantitative easing amongst other factors. ${ }^{5}$

\footnotetext{
${ }^{4}$ In general the falling trend can be explained by expansionary monetary policies after having a better control of inflation since the 1990s.

${ }^{5}$ See, Joyce and Tong (2012) for an extensive discussion on the effects of quantitative easing on the gilt market.
} 
Figure 1: Time-Series Plots for FTSE 100, Stoxx 600, Sterling, and 10-year gilt

FTSE 100

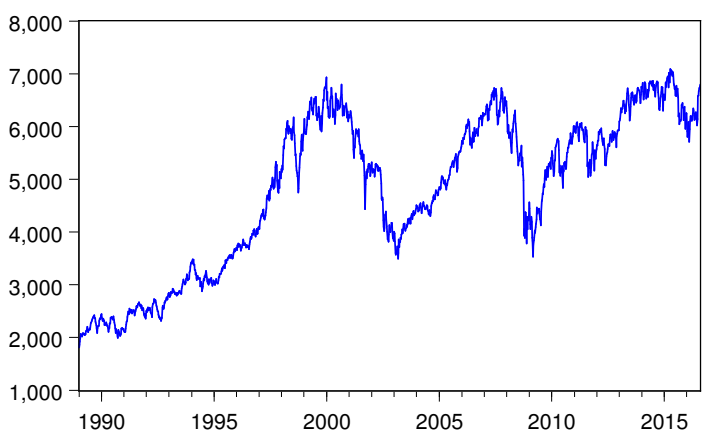

Sterling

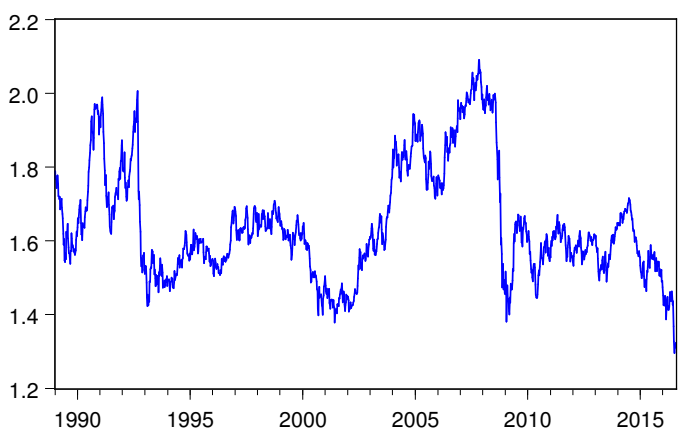

Stoxx 600

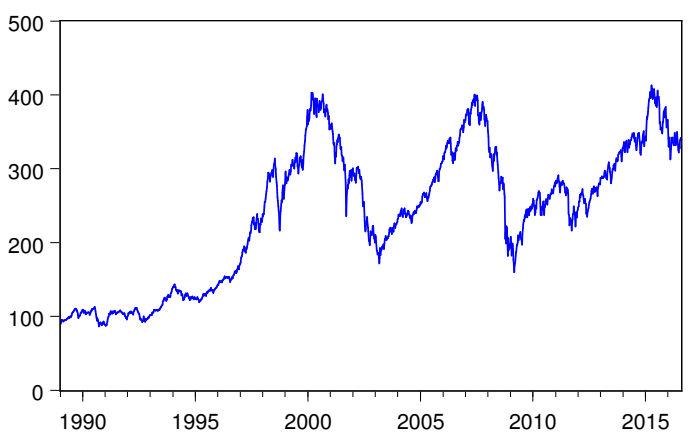

10-year Gilt

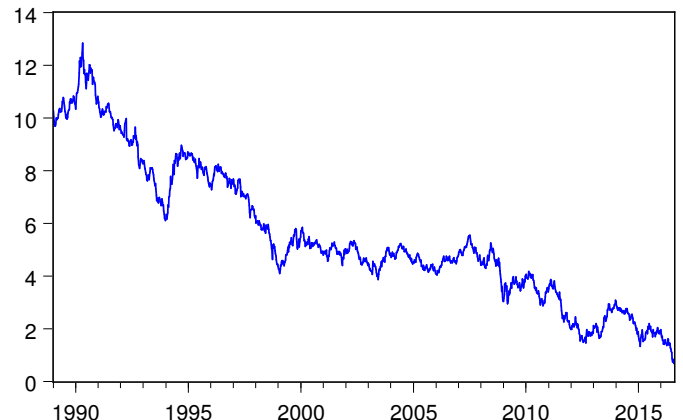

The descriptive statistics of returns on equities, bond and currency are presented in Table 1. All returns reported in Table 1 are based on continuously compounded returns which has the following expression:

$$
r_{t}=\log \left(\frac{x_{t}}{x_{t-1}}\right) \times 100
$$

where $x_{t}$ represents the weekly time series on FTSE 100, Stoxx 600, Sterling, and 10-year gilt as shown in Figure 1

The average growth rates for sterling and bond yields are negative while being positive for the three stock indices. Amongst the stock indices, FTSE 250 has the highest average growth rate, suggesting that the UK domestic economy had better performance compare to the EU. The FTSE 250 has slightly lower minimum and maximum value, indicating a mild deviation during the sample period. All five indices have negative skewness and large positive kurtosis, suggesting more negative extreme values than positive ones. Sterling and bond yield indices have negative means, suggesting an downward slopping direction for these two series in general. The $p$-value for the Jarque-Bera test confirms the non-normality for all five series. 
Table 1: Descriptive Statistics of the Returns

\begin{tabular}{l|l|l|l|l|l}
\hline & Sterling & FTSE 100 & FTSE 250 & Stoxx 600 & 10 -year gilt \\
\hline Minimum & -10.288 & -23.632 & -16.516 & -24.252 & -22.984 \\
1st Quantile & -0.764 & -1.199 & -0.975 & -1.181 & -1.649 \\
Median & 0.049 & 0.212 & 0.268 & 0.306 & -0.198 \\
3rd Quantile & 0.815 & 1.404 & 1.392 & 1.502 & 1.406 \\
Maximum & 5.195 & 12.584 & 10.400 & 12.437 & 21.317 \\
Mean & -0.022 & 0.092 & 0.144 & 0.094 & -0.189 \\
Std. Dev. & 1.331 & 2.328 & 2.259 & 2.446 & 3.319 \\
Skewness & -0.705 & -0.776 & -0.728 & -0.927 & -0.046 \\
Kurtosis & 7.315 & 12.531 & 7.703 & 11.926 & 9.469 \\
Jarque-Bera & 1235.723 & 5591.396 & 1453.127 & 4983.783 & 2509.923 \\
Kurtosis & 7.315 & 12.531 & 7.703 & 11.926 & 9.469 \\
Jarque-Bera & 0 & 0 & 0 & 0 & 0 \\
Observations & 1439 & 1439 & 1439 & 1439 & 1439 \\
\hline
\end{tabular}

\section{Marginal Distributions}

To investigate the relationship amongst stock, bond and foreign exchange markets, we model in total eight bivariate dependence structures in this paper, i.e., Sterling-FTSE 100, Sterling-FTSE 250, Sterling-Stoxx 600, Sterling-10-year gilt, FTSE 100-10-year gilt, FTSE 250-10-year gilt, FTSE 100-Stoxx 600, and FTSE 250-Stoxx 600. We adopt Patton (2006a)'s two-step estimation method to estimate copula: first, the estimation of the marginal distributions and second, the estimation of the copula parameter. Thus, for the first step, we consider AR-GJR-GARCH models (see Section 2.1 for more detail about this model), the specification of which is decided by a series of tests. 
Table 2: Test for Specification of Marginal Distribution Sterling FTSE 100 FTSE 250 Stoxx 600 10-year gilt

\begin{tabular}{l|lllll}
\hline \multicolumn{7}{l}{ Panel A Test for Conditional Mean Models } \\
Ljung-Box (5) statistics & 6.876 & 5.989 & 6.161 & 8.184 & 7.144 \\
Ljung-Box (5) p-value & 0.230 & 0.307 & 0.291 & 0.146 & 0.210 \\
Wald (chi-square) statistics & 4.826 & 16.261 & 20.483 & 10.879 & 11.434 \\
Wald (chi-square) p-value & 0.438 & 0.006 & 0.001 & 0.054 & 0.043 \\
\hline Panel B: Test for Conditional Variance Models & & \\
Constant volatility & 3.416 & 4.511 & 4.448 & 4.621 & 5.239 \\
ARCH(1,1) & 3.362 & 4.474 & 4.364 & 4.544 & 5.060 \\
GARCH(1,1) & 3.290 & 4.358 & 4.252 & 4.401 & 4.741 \\
GJR-GARCH(1,1,1) & 3.292 & 4.311 & 4.219 & 4.355 & 4.737 \\
ARCH(2) & 3.339 & 4.415 & 4.314 & 4.458 & 4.962 \\
GARCH(2,2) & 3.298 & 4.367 & 4.261 & 4.408 & 4.750 \\
GJR-GARCH(2,2,2) & 3.303 & 4.326 & 4.233 & 4.368 & 4.751 \\
\hline Panel C: Test for Standardised Residuals & & & \\
B-G LM(1) & 0.20 & 0.16 & 0.98 & 0.34 & 0.42 \\
B-G LM(2) & 0.40 & 0.36 & 0.77 & 0.41 & 0.57 \\
K-S p-value & 1 & 1 & 1 & 1 & 1 \\
\hline
\end{tabular}

Note: Panel A presents the test statistics and p-values from Ljung-Box test for serial correlation in the residuals from the AR models, and the Wald test statistics and p-values for cross-variable effect between Sterling and other variables. Panel B presents the BIC values of the GJR-GARCH models. Panel C presents the p-values from Breusch-Godfrey LM tests of serial independence of the first two moments of the variables $U_{t}$ and $V_{t}$, and the Kolmogorov-Smirnov test to see if the variables $U_{t}$ and $V_{t}$ are uniformly distributed.

Table 2 presents details of the test results for the first four bivariate data sets. ${ }^{6}$ The optimal lag length of the AR model is selected by applying the Bayesian information criterion (BIC), and further confirmed by a Ljung-Box test for autocorrelation. As the results show, no serial correlation is found for the residuals from the AR models up to $\operatorname{lag} 5$.

Cross-variable effects are also tested for any potential lead-lag relationship. As suggested by the Wald test in Panel A of Table 2, we do have to include some cross-variable lags for the regressions of stock on sterling and bond on sterling, while no cross-variable effect is found from sterling to stock and bond. We only include those cross-variable lags that are statistically significant. The cross-variable test suggests that sterling is relatively independent from stock and bond movements, while the movement of sterling itself can influence the other two markets.

To estimate the conditional variance, we consider the GJR-GARCH model, as this model allows for asymmetric information between return and volatility. Seven nested GJRGARCH models are compared and the optimal model for the conditional variance is the one that have the lowest BIC value. As can be seen from Panel B of Table 2,

\footnotetext{
${ }^{6}$ The results presented are for Sterling-FTSE 100, Sterling-FTSE 250, Sterling-Stoxx 600, Sterling10-year gilt. For each bivariate set, two series will be tested. We only present test results for Sterling once to avoid repetition. Test results for the rest four bivariate data sets can be obtained upon request to the authors.
} 
Table 3: Marginal Distribution Model

Panel 1: Conditional Mean Models

\begin{tabular}{|c|c|c|c|c|c|}
\hline & Sterling & FTSE 100 & FTSE 250 & Stoxx 600 & 10-year gilt \\
\hline Constant (M) & $\begin{array}{l}-0.022 \\
(0.035)\end{array}$ & $\begin{array}{l}0.089 \\
(0.061)\end{array}$ & $\begin{array}{l}0.109^{*} \\
(0.059)\end{array}$ & $\begin{array}{l}0.083 \\
(0.064)\end{array}$ & $\begin{array}{l}-0.193^{* *} \\
(0.088)\end{array}$ \\
\hline$\overline{\mathrm{AR}(1)}$ & & $\begin{array}{l}-0.062^{* *} \\
(0.026)\end{array}$ & $\begin{array}{l}0.070^{* *} \\
(0.026)\end{array}$ & $\begin{array}{c}-0.049^{*} \\
(0.026)\end{array}$ & $\begin{array}{c}-0.053^{* *} \\
(0.026)\end{array}$ \\
\hline $\operatorname{AR}(2)$ & & $\begin{array}{l}0.032 \\
(0.026)\end{array}$ & $\begin{array}{l}0.082^{* *} \\
(0.026)\end{array}$ & $\begin{array}{l}0.067^{* *} \\
(0.026)\end{array}$ & \\
\hline $\operatorname{AR}(3)$ & & $\begin{array}{l}-0.086^{* *} \\
(0.026)\end{array}$ & & & \\
\hline Cross-variable (1) & & & $\begin{array}{l}-0.118^{* *} \\
(0.044)\end{array}$ & & \\
\hline Cross-variable (2) & & $\begin{array}{c}-0.088^{*} \\
(0.046)\end{array}$ & & $\begin{array}{l}-0.097^{* *} \\
(0.049)\end{array}$ & \\
\hline Cross-variable (4) & & & & & $\begin{array}{l}0.132^{* *} \\
(0.066)\end{array}$ \\
\hline Cross-variable (5) & & $\begin{array}{l}-0.104^{* *} \\
(0.046)\end{array}$ & $\begin{array}{l}-0.115^{* *} \\
(0.044)\end{array}$ & $\begin{array}{l}-0.101^{* *} \\
(0.048)\end{array}$ & \\
\hline
\end{tabular}

Panel 2: Conditional Variance Models

\begin{tabular}{|c|c|c|c|c|c|}
\hline & Sterling & FTSE 100 & FTSE 250 & Stoxx 600 & 10-year gilt \\
\hline \multirow[t]{2}{*}{$\overline{C s t}(\mathrm{~V})$} & $0.068^{* *}$ & $0.245^{* *}$ & $0.326^{* *}$ & $0.347^{* *}$ & $0.095^{* *}$ \\
\hline & $(0.001)$ & $(0.005)$ & $(0.005)$ & $(0.006)$ & $(0.001)$ \\
\hline \multirow[t]{2}{*}{$\mathrm{ARCH}(1)$} & $0.098^{* *}$ & $0.000^{* *}$ & $0.021^{* *}$ & $0.012^{* *}$ & $0.072^{* *}$ \\
\hline & $(0.000)$ & $(0.000)$ & $(0.000)$ & $(0.000)$ & $(0.000)$ \\
\hline \multirow[t]{2}{*}{ GJR(1) } & & $0.220^{* *}$ & $0.229^{* *}$ & $0.274^{* *}$ & $0.083^{* *}$ \\
\hline & & $(0.001)$ & $(0.002)$ & $(0.002)$ & $(0.001)$ \\
\hline \multirow[t]{2}{*}{ GARCH(1) } & $0.865^{* *}$ & $0.844^{* *}$ & $0.794^{* *}$ & $0.788^{* *}$ & $0.884^{* *}$ \\
\hline & $(0.001)$ & $(0.001)$ & $(0.001)$ & $(0.001)$ & $(0.000)$ \\
\hline
\end{tabular}

Note: This table presents the estimated parameters and the standard errors of the conditional marginal distributions. Panel 1 reports quasi maximum likelihood standard errors while in Panel 2 the standard errors are calculated by the inverse analytical hessian. **: Significant at 5\% level; *: Significant at 10\% level.

stock and bond movements are better captured by GJR-GARCH $(1,1,1)$ models while a GARCH $(1,1)$ seems to be the best fit for movements in sterling. The estimated results of the marginal distributions are presented in Table 3. As can be seen, specifications of the marginal distributions for the three stock indices are quite similar. Both have positive asymmetric parameters, very close autoregressive conditional heteroscedasticity (ARCH) and GARCH parameters.

To model the distribution of the standardised residuals, we apply a non-parametric method as introduced in Section 2.1, where the margins are obtained by applying the empirical distribution function. One of the advantages of using the EDF is that it is invariant to the choice of the margins and thus avoids any misspecification at this step. The empirical distribution function transforms the univariate random variables into a uniformly distributed random pair $(U, V)$. 
Test results for the misspecification of the marginal distribution of the standardised residuals are presented in Panel C of Table 2. As can be seen, the LM Breusch-Godfrey test confirms there is no serial correlation with the first and second moments, and the $p$-values of the Kolmogorov-Smirnov $(\mathrm{KS})$ test are equal to 1 , indicating that $(U, V)$ are indeed uniformly distribution random pairs.

\section{Modelling Bivariate Tail Dependence between Stock, Bond and Foreign Exchange Markets}

In this section, we adopt a copula-based approach to model the dependence structure between extreme events in financial markets beyond the conventional dependence measures, Pearson correlation (see, e.g., Embrechts et al., 2002). In particular, dependencies between extreme events such as extreme negative stock returns or large portfolio losses causes the need for alternative dependence measures to support beneficial asset allocation strategies. In this regard, we follow Frahm et al. (2005)'s nonparametric estimation method to obtain the tail dependence coefficients. The tail dependence coefficients provide a measure of probability that one variable is extremely positive/negative given that the other one is extremely positive/negative, which could translate into improved diversification or hedging opportunities in the case of asset returns.

Table 4: Non-parametric Estimates of Tail Dependence

\begin{tabular}{l|ll|lll}
\hline & \multicolumn{3}{|c|}{ Lower Tail } & \multicolumn{3}{c}{ Upper Tail } \\
\hline & "LOG" & "SEC" & "LOG" & "SEC" & $\lambda_{L}=\lambda_{U}$ \\
\hline \multirow{2}{*}{ Sterling-FTSE 100 } & 0.059 & 0.059 & 0.047 & 0.048 & 0.512 \\
& {$[0,0.375]$} & {$[0,0.379]$} & {$[0,0.377]$} & {$[0,0.379]$} & \\
\hline \multirow{2}{*}{ Sterling-FTSE 250 } & 0.073 & 0.073 & 0.033 & 0.035 & 0.569 \\
& {$[0,0.403]$} & {$[0,0.414]$} & {$[0,0.382]$} & {$[0,0.384]$} & \\
\hline \multirow{2}{*}{ Sterling-Stoxx 600 } & 0.098 & 0.100 & 0.073 & 0.073 & 0.499 \\
& {$[0,0.411]$} & {$[0,0.415]$} & {$[0,0.365]$} & {$[0,0.368]$} & \\
\hline \multirow{2}{*}{ Sterling-10-year gilt } & 0.035 & 0.038 & 0.112 & 0.113 & 0.358 \\
& {$[0,0.391]$} & {$[0.0 .399]$} & {$[0,0.435]$} & {$[0,0.434]$} & \\
\hline \multirow{2}{*}{ FTSE 100-10-year gilt } & 0.130 & 0.132 & 0.120 & 0.121 & 0.507 \\
& {$[0,0.453]$} & {$[0,0.453]$} & {$[0,0.444]$} & {$[0,0.446]$} & \\
\hline \multirow{2}{*}{ FTSE 250-10-year gilt } & 0.092 & 0.095 & 0.118 & 0.118 & 0.489 \\
& {$[0,0.397]$} & {$[0,0.396]$} & {$[0,0.451]$} & {$[0,0.452]$} & \\
\hline \multirow{2}{*}{ FTSE 100-Stoxx 600 } & 0.598 & 0.601 & 0.523 & 0.525 & 0.45 \\
& {$[0.238,0.872]$} & {$[0.239,0.877]$} & {$[0.172,0.757]$} & {$[0.173,0.765]$} \\
\hline \multirow{2}{*}{ FTSE 250-Stoxx 600 } & 0.532 & 0.534 & 0.416 & 0.419 & 0.447 \\
& {$[0.131,0.776]$} & {$[0.131,0.785]$} & {$[0.111,0.707]$} & {$[0.112,0.715]$} \\
\hline
\end{tabular}

Notes: The above table calculates the upper and lower tail dependence coefficients separately using two different methods - the LOG estimator and the SEC estimator as described in Section 2.2. Both the tail dependence coefficients and the corresponding $90 \%$ confidence intervals are reported assuming $q=0.1$ for the whole sample. Details for testing of asymmetric dependence can be found in Section 2.3.

Table 4 presents the tail dependence coefficients from two non-parametric estimators, the "LOG" estimator and the "SEC" estimator. The reason for choosing two estimators, as described in Section 2.2, is to protect against any misspecification from a trade-off 
between the estimator and its bias. As Table 4 reveals, the tail dependence coefficients are quite similar across the two estimation methods. We further model the upper and lower tails separately to capture the asymmetric dependence. The last column of Table 4 presents $p$-values of the statistical test as described in Section 2.3. Implementing the joint test on the estimated dependence function, with $q \in\{0.025,0.05,0.10,0.975,0.95,0.90\}$ yields a chi-squared statistic, and corresponding $p$-value. As indicated by the $p$-value, we fail to reject the hypothesis that the dependence structure is symmetric using this metric. Since there is no evidence for extreme asymmetries between positive and negative shocks, we therefore will focus on the lower-tail dependence.

Table 5: Parametric Estimates of Tail Dependence

\begin{tabular}{l|ll|lll}
\hline & \multicolumn{3}{|c|}{ Lower Tail } & \multicolumn{3}{c}{ Upper Tail } \\
\hline & "Gumbel" & "Student's $t "$ & "Gumbel " & "Student's $t "$ & $\lambda_{L}=\lambda_{U}$ \\
\hline \multirow{2}{*}{ Sterling-FTSE 100 } & 0.058 & 0.017 & 0.040 & 0.009 & 0.470 \\
& {$[0,0.402]$} & {$[0,0.057]$} & {$[0,0.478]$} & {$[0,0.028]$} & \\
\hline \multirow{2}{*}{ Sterling-FTSE 250 } & 0.080 & 0.026 & 0.036 & 0.004 & 0.540 \\
& {$[0,0.425]$} & {$[0,0.064]$} & {$[0,0.330]$} & {$[0,0.094]$} & \\
\hline \multirow{2}{*}{ Sterling-Stoxx 600 } & 0.096 & 0.016 & 0.073 & 0.104 & 0.499 \\
& {$[0,0.402]$} & {$[0,0.061]$} & {$[0,0.375]$} & {$[0.095,0.195]$} \\
\hline \multirow{2}{*}{ Sterling-10-year gilt } & 0.033 & 0.006 & 0.098 & 0.006 & 0.530 \\
& {$[0,0.383]$} & {$[0.0 .020]$} & {$[0,0.413]$} & {$[0,0.019]$} & \\
\hline \multirow{2}{*}{ FTSE 100-10-year gilt } & 0.132 & 0.015 & 0.120 & 0.012 & 0.530 \\
& {$[0,0.403]$} & {$[0,0.042]$} & {$[0,0.444]$} & {$[0,0.043]$} & \\
\hline \multirow{2}{*}{ FTSE 250-10-year gilt } & 0.107 & 0.020 & 0.118 & 0.018 & 0.280 \\
& {$[0,0.403]$} & {$[0,0.046]$} & {$[0,0.432]$} & {$[0,0.055]$} & \\
\hline \multirow{2}{*}{ FTSE 100-Stoxx 600 } & 0.565 & 0.406 & 0.496 & 0.262 & 0.540 \\
& {$[0.364,0.799]$} & {$[0.212,0.630]$} & {$[0.271,0.517]$} & {$[0.162,0.383]$} \\
\hline \multirow{2}{*}{ FTSE 250-Stoxx 600 } & 0.526 & 0.390 & 0.379 & 0.010 & 0.400 \\
& {$[0.372,0.749]$} & {$[0.287,0.523]$} & {$[[0.130,0.577]$} & {$[0.009,0.061]$} \\
\hline
\end{tabular}

Notes: The estimates are based on Gumbel and student's $t$ copula for the upper tail, and the rotated Gumbel and student's $t$ copula for the lower tail. Both the tail dependence coefficients and the corresponding 90\% confidence intervals are reported assuming $q=0.1$ for the whole sample. Details for testing of asymmetric dependence can be found in Section 2.3.

Table 5 provides estimates of tail dependence coefficient from a parametric approach. We use the probability integral transformation function to model the standardised residuals. After testing a series of distributions, including Gaussian, Student's t, Generalised Error Distribution (GED) and skewed $t$ distribution using the Kolmogorov-Smirnov test, we confirm that Hansen (1994)'s skewed $t$ distribution has the lowest $p$-value and hence is the most appropriate distribution for the conditional distribution of the standardised residuals. For the tail dependence parameter, we adopt Chen et al. (2010)'s parametric maximum log-likelihood estimation method for the estimation of tail copula parameter, where the log-likelihood function is given by

$$
\begin{gathered}
\log L\left(U_{1 t}, U_{2 t}, \delta_{1 t}, \delta_{2 t} ; \theta\right)=\delta_{1 t} \delta_{2 t} \log c\left(U_{1 t}, U_{2 t} ; \theta\right) \\
+\delta_{1 t}\left(1-\delta_{2 t}\right) \log \frac{\partial C\left(U_{1 t}, U_{2 t} ; \theta\right)}{\partial u}+\left(1-\delta_{1 t}\right) \delta_{2 t} \log \frac{\partial C\left(U_{1 t}, U_{2 t} ; \theta\right)}{\partial u} \\
+\left(1-\delta_{1 t}\right)\left(1-\delta_{2 t}\right) \log C\left(U_{1 t}, U_{2 t} ; \theta\right)
\end{gathered}
$$


where $c\left(U_{1 t}, U_{2 t} ; \theta\right)=\frac{\partial^{2} C\left(U_{1 t}, U_{2 t} ; \theta\right)}{\partial U_{1 t} \partial U_{2 t}}$ is the density function of copula $C\left(U_{1 t}, U_{2 t} ; \theta\right)$. Maximising the above function yields a parameter $\theta$ for the selected copula. For a detailed discussion on this approach, see, the original contribution Chen et al. (2010) and Patton (2013).

Estimation of this tail dependence coefficient requires the choice of the quantile $q$. When $q$ is small enough or is approaching zero, the corresponding quantile measure can be treated as tail dependence. For each censoring variable $q$, we can get a tail copula parameter by maximising Equation (17), and the tail dependence parameter can be obtained by applying Equation (6) .

Table 5 presents the tail copula parameters and the corresponding $90 \%$ confidence intervals based on two copulas: the student's $t$ copula and the Gumbel copula using the above method. In summary, the parametric and nonparametric estimates show that the upper and lower tail dependence coefficients are very similar across three of the four methods, with the tail dependence implied by the Student's $t$ copula being lower than the other three estimates.

To explain our results, we first focus on the dependence of the currency market with other markets as reported in the upper-half of Table 4. Overall, the currency market has a weak tail-dependence with both the EU and UK equity markets, suggesting that contagion effect even under extreme fluctuations is limited. Focusing on the lower taildependence, our results indicate that if there is an extreme negative shock in the currency market, the probability that FTSE 100 and FSTE 250 will experience a similar negative shock is $5.9 \%$ and $7.2 \%$, respectively.

Overall, the weak lower tail dependence between the British equity and currency markets to a certain degree can be explained by increased export-earnings of the companies with international businesses, directly benefiting from sterling depreciations. On the other hand, the weak upper tail dependence could possibly be due to decreasing costs of importing companies. Hence, the relationship between stock and currency markets up to a certain degree is dependent on the nature of trade, i.e. whether the company mainly exports or imports as also discussed in Granger et al. (2000). In general, existing literature reveals equivocal evidence regarding the dependence between currency and equity markets (see, e.g., Griffin and Stulz, 2001; Cumperayot et al., 2006; Fang, 2010).

In the wake of Brexit, it is not surprising that the stock market initially fell but then recovered quickly, reaching its pre-Brexit levels, while the currency stabilised at a lower level than its pre-Brexit level. During the phases of currency short-selling due to uncertainty or quantitative easing, FTSE 250, a gauge of the domestic economy, maybe slightly more sensitive than the more global and diversified blue-chip FTSE 100. However, it can be argued that currency fluctuations in Britain may not have a very strong direct impact on the British equity market in general.

The currency market also has a weak tail-dependence with the bond yield. The results, however, reveal evidence of asymmetric dependence, where the upper tail dependence co- 
efficient is 0.112 and the lower tail dependence coefficient is only 0.035 . This asymmetry could be due to the relatively stable history of the UK government bond, making it an attractive spot for international capital. In particular, the higher upper tail dependence between sterling and bond yield, can be explained by two main channels: i) the direct effects of currency shocks on the bond market, i.e., if the value of sterling appreciates, international traders directly experience higher returns on their bond holdings, ii) an increased yield on the UK bond market attracts a large number of international investors, causing an appreciation of the pound. In contrast, a fall in gilt yield is likely to cause depreciation of the sterling. However, this effect is much weaker as international investors consider the risk-reward scenarios, i.e. lower bond-yields do not tend to induce capital outflows, thus, having no major impact on the currency market. Another plausible reason for the presence of asymmetry in the dependence structure could be due to the asymmetric preferences of monetary policy authorities in the UK as discussed in Caglayan et al. (2016).

We now turn to the analyses of equity market as reported in the lower-half of Table 4. The tail dependence in the case of bond-equity, although weak in general, is still higher than the tail dependence in the case of bond-currency. In particular, if there are negative shocks in the equity market, the probability of bond market experiencing negative shocks is $12.9 \%$ in the case of FTSE 100 shocks, and 9.2\% in the case of FTSE 250 shocks. The weak co-movement between stock prices and bond yields is consistent with the stylised fact that higher interest rates generally lead to a slowdown in the stock market activities. Finally, our results indicate strong tail-dependence between the UK and EU equity markets due to strong economic integration between these two markets. If there are negative shocks in the UK equity market, the probability of EU equity market experiencing negative shocks is $59.1 \%$ in the case of FTSE 100 shocks, and $53.1 \%$ in the case of FTSE 250 shocks. This finding is consistent with the existing literature which widely concludes a strong positive co-movement between the equity markets of the two regions.

\section{Modelling Quantile Dependence between Stock, Bond and Foreign Exchange Markets}

In this section, we draw on extreme value theory and consider the quantile dependence measure, which in its classical definition quantifies the strength of dependence between two variables when they are jointly low or high. The quantile dependence provides a richer dependence structure than the tail dependence presented in the previous section. By comparing the upper and lower quantile, we are provided with more detailed information about the dependence structure, e.g., the asymmetric dependence.

Using the methodology presented in Section 2.3, we calculated the dependence at different quantile levels between stock, bond, and foreign exchange markets. Similar to the tail dependence, eight dependency coefficients and their corresponding confidence intervals are presented. 
Table 6a: Non-parametric Estimates of Quantile Dependence

\begin{tabular}{l|l|l|l|l}
\hline & Sterling-FTSE100 & Sterling-FTSE250 & Sterling-Stoxx600 & Sterling-Gilt \\
\hline $\mathrm{q}=0.1$ & 0.098 & 0.173 & 0.190 & 0.173 \\
& {$[0.053,0.141]$} & {$[0.133,0.212]$} & {$[0.148,0.231]$} & {$[0.132,0.212]$} \\
$\mathrm{q}=0.3$ & 0.260 & 0.351 & 0.380 & 0.373 \\
& {$[0.221,0.298]$} & {$[0.319,0.382]$} & {$[0.346,0.413]$} & {$[0.339,0.405]$} \\
$\mathrm{q}=0.5$ & 0.458 & 0.530 & 0.545 & 0.559 \\
& {$[0.421,0.493]$} & {$[0.503,0.556]$} & {$[0.517,0.572]$} & {$[0.531,0.586]$} \\
$\mathrm{q}=0.7$ & 0.254 & 0.368 & 0.402 & 0.409 \\
& {$[0.184,0.323]$} & {$[0.321,0.414]$} & {$[0.3553,0.448]$} & {$[0.362,0.454]$} \\
$\mathrm{q}=0.9$ & 0.082 & 0.192 & 0.206 & 0.214 \\
& {$[-0.084,0.249]$} & {$[0.088,0.295]$} & {$[0.1048,0.306]$} & {$[0.107,0.320]$} \\
\hline Testing for Asymmetry & 0.341 & 0.659 & 0.537 & 0.829 \\
\hline
\end{tabular}

Table $6 \mathrm{a}$ and $6 \mathrm{~b}$ reports the non-parametric estimates of quantile dependence between different markets. We first focus on the dependence structure of currency with other variables. Overall, the shocks in the currency market at different quantiles reveal a weak comovement with the bond and equity markets. In particular, extreme shocks in the currency market show a very weak comovement with FTSE 100, as represented by quantile dependence coefficients of 0.098 at quantile $(q=0.1)$ and 0.082 at quantile $(q=0.9)$. Extreme currency shocks, however, indicate a relatively stronger comovement with FTSE 250, Stoxx 600, and gilt as compared to FTSE 100. The strength of comovement of sterling with FTSE 250, Stoxx 600, and gilt is almost double than in the case of FTSE 100 at quantiles, $\mathrm{q}=0.1$, and $\mathrm{q}=0.9$. As we move towards the centre of the distribution, the comovement of currency shocks with all variables increases as expected.

Our findings once again clearly indicate that FTSE 250 index, which heavily relies on the domestic economy, is much sensitive to the events in the British economy as compared to FTSE 100 index, which is largely dependent on overseas revenues and can benefit from a devaluation in sterling. Hence, we can argue that if there are swings in the currency market either due to uncertainty or quantitative easing as a policy response from the Central Bank, investments in FTSE 100 are likely to reduce portfolio volatility. ${ }^{7}$

\footnotetext{
${ }^{7}$ Our findings are consistent with the fact that FTSE 100 includes multinational firms based in the UK, which are less sensitive to the events in domestic economy as compared to FTSE 250, as also discussed by Weale (2016) in his recent speech.
} 
Table 6b: Non-parametric Estimates of Quantile Dependence

\begin{tabular}{l|l|l|l|l|l}
\hline & FTSE100-Gilt & FTSE250-Gilt & FTSE100-Stoxx600 & FTSE250-Stoxx600 \\
\hline $\mathrm{q}=0.1$ & 0.167 & 0.195 & 0.763 & 0.728 \\
& {$[0.111,0.223]$} & {$[0.135,0.254]$} & {$[0.684,0.840]$} & {$[0.648,0.807]$} \\
$\mathrm{q}=0.3$ & 0.372 & 0.358 & 0.828 & 0.755 \\
& {$[0.326,0.417]$} & {$[0.312,0.403]$} & {$[0.786,0.870]$} & {$[0.711,0.797]$} \\
$\mathrm{q}=0.5$ & 0.531 & 0.536 & 0.864 & 0.822 \\
& {$[0.493,0.569]$} & {$[0.497,0.573]$} & {$[0.833,0.894]$} & {$[0.792,0.851]$} \\
$\mathrm{q}=0.7$ & 0.315 & 0.343 & 0.811 & 0.755 \\
& {$[0.243,0.385]$} & {$[0.270,0.414]$} & {$[0.765,0.856]$} & {$[0.708,0.801]$} \\
$\mathrm{q}=0.9$ & 0.117 & 0.166 & 0.692 & 0.609 \\
& {$[-0.056,0.290]$} & {$[-0.001,0.333]$} & {$[0.601,0.781]$} & {$[0.515,0.702]$} \\
\hline Testing for Asymmetry & 0.103 & 0.093 & 0.153 & 0.121 \\
\hline
\end{tabular}

We now turn to the dependence structure between the equity and bond markets as shown in Table 6b. Overall, extreme shocks in the British equity market show a weak comovement with the bond yield. The literature widely argues that the bond-equity relationship is time variant and is affected by economic fundamentals up to a certain degree. ${ }^{8}$ Hence, it is difficult to point out the exact factors with certainty that might be responsible for this weak comovement in our case. ${ }^{9}$ However, our finding is in contrast to the notion of "flight to safety" at a domestic level. ${ }^{10}$ This might be due to the low-yielding gilt and the thirst for income, pushing investors to diversify more globally into emerging market sovereign bonds. Finally, the British equity market indicates a very strong comovement with the EU equity market at different quantiles. In particular, the dependence between FTSE 100 and Stoxx 600 is slightly stronger than the dependence between FTSE 250 and Stoxx 600. Our findings clearly support the argument that cuts in the interest rates, which can affect the bond market, will have little impact on the equity market as the dependence between the equity and bond markets is very weak in general.

\footnotetext{
${ }^{8}$ See, e.g., Campbell and Ammer (1993); Hartmann et al. (2004); Connolly et al. (2005) for a detailed discussion on this.

${ }^{9}$ We believe that the era of expansionary monetary policies inducing investment growth, thereby driving stock prices up, are amongst the important factors contributing to a weaker comovement between stock prices and bond yields in our sample.

${ }^{10}$ Flight to quality is the action of investors moving their capital away from riskier stocks to the safer investment option such as bond. Therefore, the correlation between stock returns and bond yield is expected to be positive.
} 
Figure 2:
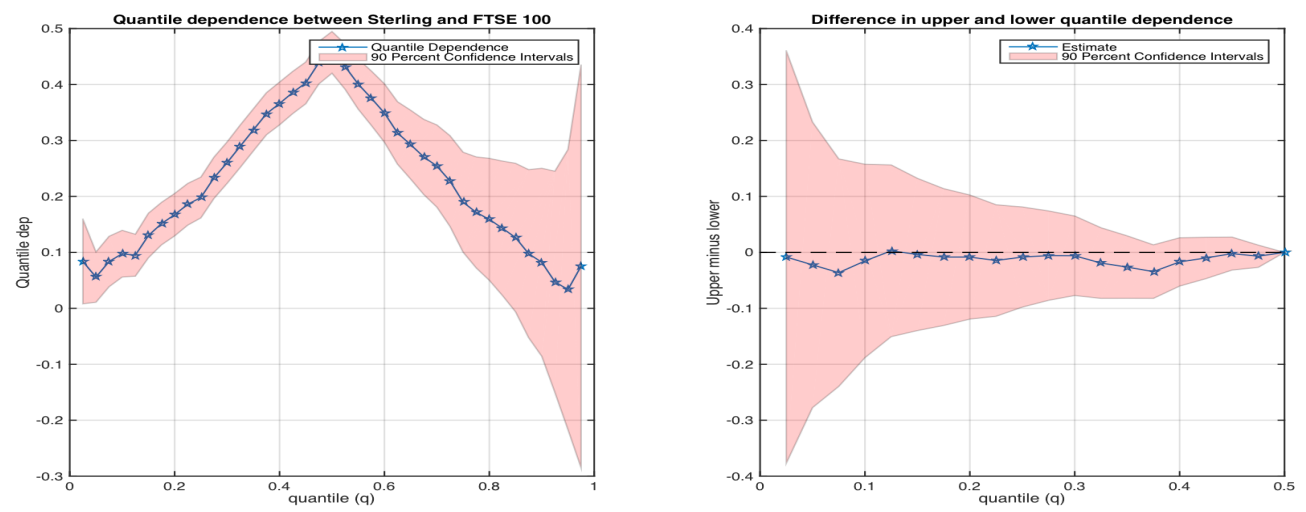

Figure 3:
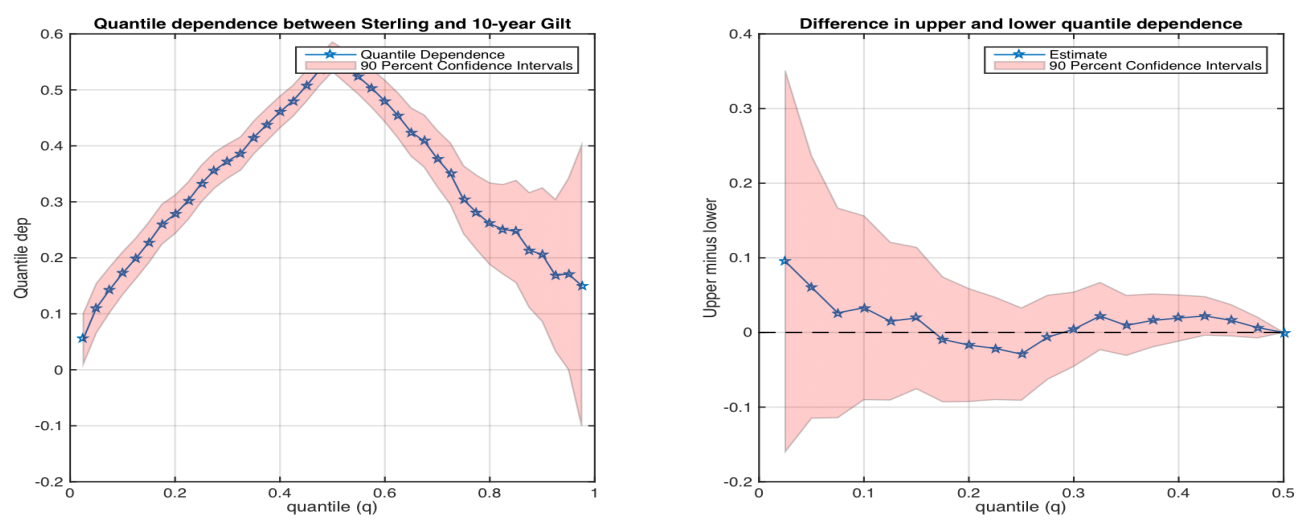

Figure 4:
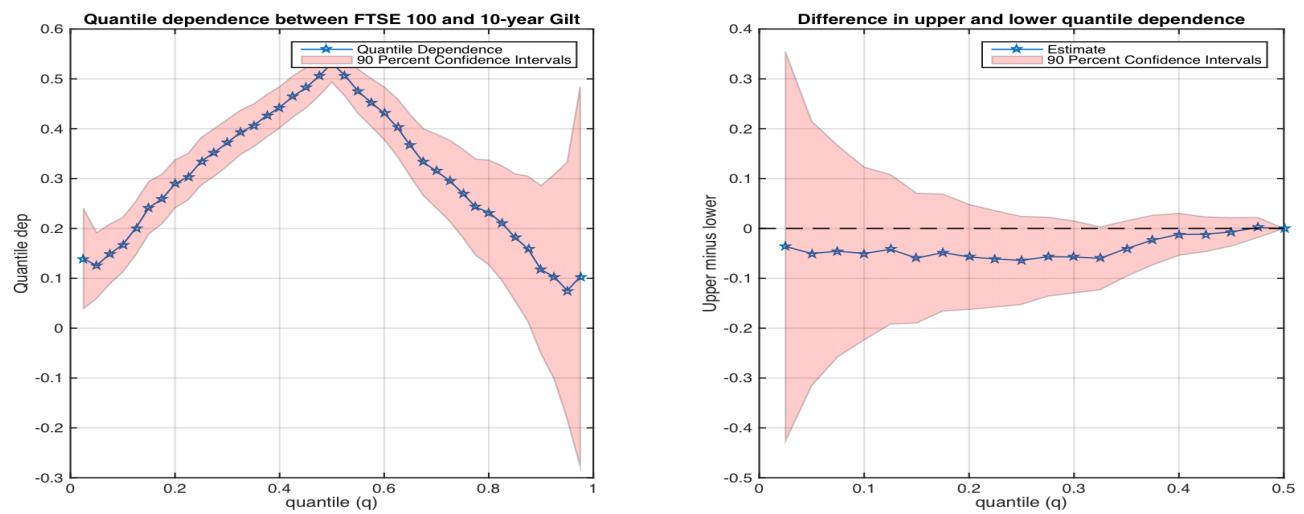
Figure 5:
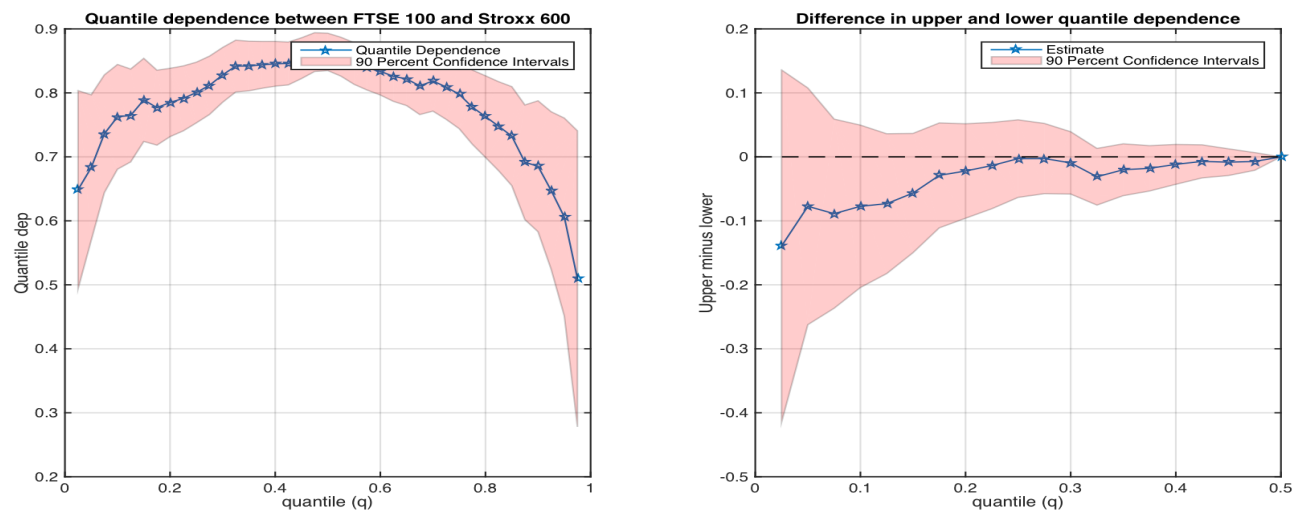

Moreover, asymmetric dependence, although not statistically significant in most cases, can be observed by comparing the dependence parameters between quantile $q$ and $1-q$. The dependence for FTSE 100 and 10-year gilt at quantile 0.7 and 0.9 are 0.3147 and 0.1172 , while the dependence at quantile 0.3 and 0.1 are 0.3719 and 0.1674 , indicating the existence of the asymmetric dependence. This is further confirmed by Figure 4, where the difference of the upper and lower quantile are calculated. It clearly shows that the differences are below zero, which points to the existence of asymmetry.

Regarding Brexit, it is almost impossible to quantify or predict the effects of such an event due to uncertainty over the terms and conditions of UK's future relationship with the EU. In the context of Brexit, we explain our results with great caution. Overall, our findings can be interpreted to indicate a weak comovement amongst currency, bond and equity markets in the UK. It is worth highlighting that the time frame we analysed in our empirical analyses covers several events of financial turbulence, including the initial reaction of the markets to the news of Brexit. Thus, an important question is that, can the implications of our findings be extended to the next few years leading to Brexit and the post-Brexit period. An important aspect of Brexit is that it is an awaited event, i.e., it will not come as a surprise in the financial markets. The news of Brexit as a shock has already been experienced by the markets. Therefore, minor or expected developments in the years leading to Brexit are expected to generate fluctuations in the currency market from time to time but this will not greatly affect the bond and equity markets, as indicated by our findings. From a risk management perspective, the evidence presented in this paper indicates that FTSE 100 is relatively less volatile and more suitable asset to reduce portfolio risks, especially when swings in the currency market are most likely.

In contrast, if there are major political and economic shifts as a result of Brexit, e.g., enforcing new rules and regulations on trade and cross-border flow of capital, we believe the dependence structure amongst currency, bond and equity markets might change. If we treat Brexit as any other crisis, one might argue that the empirical results of this study will remain valid even in the post-Brexit period. However, it is widely expected that the event of Brexit per se is going to be far greater in its scale than the events of the past few decades in the UK. In addition, there is also an important difference in the 
event of Brexit and other crises that have occurred in the last two decades. Almost all other major crises, covered by our analyses, erupted elsewhere and then spread to the UK economy, having a limited impact on the British financial markets as compared to the countries from where the crises originated. The limited impact of those crises on the financial markets amongst other things can also be explained by the status of the UK as one of the greatest financial hubs in the world. In contrast, the countries where the crises initially erupted experienced huge systemic risks and usually suffered the most both in terms of impact and duration such as Greece, Iceland, and Ireland.

While the expectation of Brexit allows market participants to prepare for an adverse event in advance, what is completely unknown is how the event will unfold in the coming few years. There are also fears that Britain might lose its current status of serving as one of the greatest hubs of financial activities, which has greatly contributed to its financial stability. In the case of major political and economic disruptions, we argue that the dependence structure between equity and currency markets may change, whereas the comovement of bond yields with the other two markets may remain weak, or slightly increase. In the event of a crisis, there are expectations of global flight to safety - as was also the initial reaction of the markets to the news of Brexit - in which case there will be a fall in stock returns and a short-selling of the currency, which might increase the lower tail dependence between equity and currency markets. The intensity of a fall in the stock and currency markets depends upon how much capital will flee from the British market towards other sovereign bonds. If businesses and international investors, in response to Brexit, relocate a major portion of their capital, then the economy might experience significant outflows which can trigger a financial and real economic crisis, as is evident from the historical episodes of international capital flights.

The dependence between bond yield with the equity and currency markets may remain weak in the event of a crisis. As discussed above, fears of crisis may lead to a fall in stock returns, as a consequence of global flight to safety, however, it can be argued that there will not be a huge pressure on gilt, as capital is likely to flee from the British market to other sovereign bonds. On the contrary, gilt yields might increase if there is a significant capital outflow. Thus, the comovement between stock returns and bond yields is likely to remain weak. The lower tail dependence between bond yields and stock returns may slightly increase if domestic investors with home bias switch to investing in the domestic bond market, putting downward pressure on gilt yields. However, yields on gilt are already at a very low level, hence, any further pressure on the bond market may not lead to a further decline. In addition, there are fears that inflationary forces are gaining momentum due to currency depreciation, making a fall in gilt yields unlikely. In contrast, if monetary policy authorities respond by raising interest rates due to inflation expectations, the comovement between bond yields and stock returns will further weaken.

There is also a possibility that some investors may respond by pursuing a strategy of diversification in attempts to reduce portfolio risks. Consequently, the interlinkages amongst assets will tend to increase, which might strengthen the comovement amongst currency, bond, and equity markets. It is well-known that portfolio diversification, in the presence of home bias, lowers the risk at an individual level but amplifies the risk to the whole 
system through interconnectedness, which can increase the chances of systemic risks.

From a policy perspective, Caruana (2010) has proposed a combination of different policies including, fiscal, monetary, macro- and microprudential policies in order to deal with systemic risks. From investors perspective, a viable strategy is to reduce the impact of any potential crisis by international diversification (not limited to the European market) well ahead of any major political developments that can potentially generate a full-blown financial crisis. Finally, a major concern regarding portfolio adjustments is that the process might lead to a self-fulling crisis - dealing with which remains an unresolved issue to date.

\section{Conclusion}

This paper investigated the dependence amongst the stock, bond and foreign exchange markets within the UK and between the UK and the EU market, using a copula-based approach. We implemented a non-parametric estimation method to get the tail and quantile dependence coefficients. We found that shocks in the currency market had a weak dependence with both the equity markets and bond market in general. However, currency shocks indicated a relatively stronger comovement with FTSE 250, Stoxx 600, and gilt as compared to FTSE 100. Moreover, our findings suggested that the dependence between the British equity and bond markets was weaker, whereas the dependence between British equity and the EU equity markets was very strong.

As Britain pursues an official exit from the EU in the coming few years, quantitative easing and lowering of interest rates as a policy response are widely expected. Large fluctuations in the currency market are most likely to occur during the phases of uncertainty as well as due to interest rate reductions. The implications of our results regarding Brexit are straight forward: we have empirical evidence to believe that FTSE 100 is less volatile, and a preferable choice for reducing portfolio risk during the phases of uncertainty. However, shocks in the British equity market are likely to have very strong impacts on the European equity markets. In this case, flight to safety - investment in the bond markets - seems an appropriate choice for reducing risks. 


\section{References}

Alagidede, P., Panagiotidis, T. and Zhang, X. (2011), 'Causal relationship between stock prices and exchange rates', The Journal of International Trade $\&$ Economic Development 20(1), 67-86.

Baig, T. and Goldfajn, I. (1999), 'Financial market contagion in the asian crisis', IMF staff papers 46(2), 167-195.

Bekaert, G., Harvey, C. R., Lundblad, C. T. and Siegel, S. (2013), 'The european union, the euro, and equity market integration', Journal of Financial Economics 109(3), 583603.

Caglayan, M., Jehan, Z. and Mouratidis, K. (2016), 'Asymmetric monetary policy rules for an open economy: Evidence from canada and the uk', International Journal of Finance $\&$ Economics .

Campbell, J. Y. and Ammer, J. (1993), 'What moves the stock and bond markets? a variance decomposition for long-term asset returns', The Journal of Finance 48(1), 337.

Caruana, J. (2010), 'Systemic risk: how to deal with it? 1 systemic risk: how to deal with it?', Basel: Bank for International Settlements p. 48.

Chen, X. and Fan, Y. (2006), 'Estimation of copula-based semiparametric time series models', Journal of Econometrics 130(2), 307-335.

Chen, X., Fan, Y., Pouzo, D. and Ying, Z. (2010), 'Estimation and model selection of semiparametric multivariate survival functions under general censorship', Journal of Econometrics 157(1), 129 - 142.

Chuliá, H., Martens, M. and van Dijk, D. (2010), 'Asymmetric effects of federal funds target rate changes on s\&p100 stock returns, volatilities and correlations', Journal of Banking \&5 Finance 34(4), 834-839.

Connolly, R., Stivers, C. and Sun, L. (2005), 'Stock market uncertainty and the stockbond return relation', Journal of Financial and Quantitative Analysis 40(01), 161-194.

Cumperayot, P., Keijzer, T. and Kouwenberg, R. (2006), 'Linkages between extreme stock market and currency returns', Journal of International Money and Finance 25(3), 528550 .

Dungey, M. and Martin, V. L. (2007), 'Unravelling financial market linkages during crises', Journal of Applied Econometrics 22(1), 89-119.

Ehrmann, M., Fratzscher, M. and Rigobon, R. (2011), 'Stocks, bonds, money markets and exchange rates: measuring international financial transmission', Journal of Applied Econometrics 26(6), 948-974. 
Embrechts, P., McNeil, A. J. and Straumann, D. (2002), Correlation and dependence in risk management: Properties and pitfalls, in M. A. H. Dempster, ed., 'Risk Management', Cambridge University Press, pp. 176-223. Cambridge Books Online.

Fang, W. (2010), 'The effects of currency depreciation on stock returns: evidence from five east asian economies', Applied Economics Letters 9(3), 195-199.

Frahm, G., Junker, M. and Schmidt, R. (2005), 'Estimating the tail-dependence coefficient: Properties and pitfalls', Insurance: Mathematics and Economics 37(1), 80-100.

Gagnon, J. E. (2009), 'Currency crashes and bond yields in industrial countries', Journal of International Money and Finance 28(1), 161-181.

Garcia, R. and Tsafack, G. (2011), 'Dependence structure and extreme comovements in international equity and bond markets', Journal of Banking \& Finance 35(8), 19541970 .

Genest, C. K. G. and Rivest, L. P. (1995), 'A semiparametric estimation procedure of dependence parameters in multivariate families of distributions', Biometrika 82(3), 543552 .

Grammatikos, T. and Vermeulen, R. (2012), 'Transmission of the financial and sovereign debt crises to the emu: Stock prices, cds spreads and exchange rates', Journal of International Money and Finance 31(3), 517-533.

Granger, C. W., Huangb, B.-N. and Yang, C.-W. (2000), 'A bivariate causality between stock prices and exchange rates: evidence from recent asianflu', The Quarterly Review of Economics and Finance 40(3), 337-354.

Gravelle, T., Kichian, M. and Morley, J. (2006), 'Detecting shift-contagion in currency and bond markets', Journal of International Economics 68(2), 409-423.

Griffin, J. M. and Stulz, R. M. (2001), 'International competition and exchange rate shocks: A cross-country industry analysis of stock returns', Review of Financial Studies 14(1), 215-241.

Guidolin, M. and Timmermann, A. (2006), 'An econometric model of nonlinear dynamics in the joint distribution of stock and bond returns', Journal of Applied Econometrics 21(1), 1-22.

Hansen, B. (1994), 'Autoregressive conditional density estimation', International Economic Review 35(3), 705-730.

Hartmann, P., Straetmans, S. and De Vries, C. G. (2004), 'Asset market linkages in crisis periods', Review of Economics and Statistics 86(1), 313-326.

Hau, H. and Rey, H. (2006), 'Exchange rates, equity prices, and capital flows', Review of financial studies 19(1), 273-317.

Hong, Y., Tu, J. and Zhou, G. (2007), 'Asymmetries in stock returns: Statistical tests and economic evaluation', Review of Financial Studies 20(5), 1547-1581. 
Inci, A. and Lee, B. S. (2014), 'Dynamic relations between stock returns and exchange rate changes', European Financial Management 20(1), 71-106.

Joe, H. (1997), Multivariate Models and Dependence Concepts, Chapman and Hall, London.

Jondeau, E. and Rockinger, M. (2006), 'The copula-garch model of conditional dependencies: An international stock market application', Journal of International Money and Finance 25(5), $827-853$.

Joyce, M. A. and Tong, M. (2012), 'Qe and the gilt market: a disaggregated analysis', The Economic Journal 122(564), F348-F384.

Kenourgios, D., Samitas, A. and Paltalidis, N. (2011), 'Financial crises and stock market contagion in a multivariate time-varying asymmetric framework', Journal of International Financial Markets, Institutions and Money 21(1), 92-106.

Kim, S.-J., Moshirian, F. and Wu, E. (2006), 'Evolution of international stock and bond market integration: Influence of the european monetary union', Journal of Banking \& Finance 30(5), 1507-1534.

Lin, C.-H. (2012), 'The comovement between exchange rates and stock prices in the asian emerging markets', International Review of Economics \& Finance 22(1), 161-172.

Newey, W. K. and West, K. D. (1994), 'Automatic lag selection in covariance matrix estimation', Review of Economic Studies 61(4), 631-653.

Ning, C. (2010), 'Dependence structure between the equity market and the foreign exchange market-a copula approach', Journal of International Money and Finance 29(5), 743-759.

Panchenko, V. and Wu, E. (2009), 'Time-varying market integration and stock and bond return concordance in emerging markets', Journal of Banking \& Finance 33(6), 10141021.

Patton, A. (2013), Chapter 16 - copula methods for forecasting multivariate time series, in G. Elliott and A. Timmermann, eds, 'Handbook of Economic Forecasting', Vol. 2, Part B, Elsevier, pp. 899-960.

Patton, A. J. (2006a), 'Estimation of multivariate models for time series of possibly different lengths', Journal of Applied Econometrics 21(2), 147-173.

Patton, A. J. (2006b), 'Modelling asymmetric exchange rate dependence', International Economic Review 47(2), 527-556.

Phylaktis, K. and Ravazzolo, F. (2005), 'Stock prices and exchange rate dynamics', Journal of International Money and Finance 24(7), 1031-1053.

Schmidt, R. and Stadtmuller, U. (2006), 'Non-parametric estimation of tail dependence', Scandinavian Journal of Statistics 33(2), 307-335. 
Syllignakis, M. N. and Kouretas, G. P. (2011), 'Dynamic correlation analysis of financial contagion: Evidence from the central and eastern european markets', International Review of Economics \&6 Finance 20(4), 717-732.

Tudor, C. and Popescu-Dutaa, C. (2012), 'On the causal relationship between stock returns and exchange rates changes for 13 developed and emerging markets', ProcediaSocial and Behavioral Sciences 57, 275-282.

Weale, M. (2016), 'Brexit and monetary policy', Speech: Bank of England .

Yu, I.-W., Fung, K.-P. and Tam, C.-S. (2010), 'Assessing financial market integration in asia-equity markets', Journal of Banking \& Finance 34(12), 2874-2885.

Zhang, S., Paya, I. and Peel, D. (2009), 'Linkages between Shanghai and Hong Kong stock indices', Applied Financial Economics 19(23), 1847-1857. 